\title{
Preparation and Characterization of Poly(vinylpyrrolidone)/ Zirconium Oxide Hybrids by Using Inorganic Nanocrystals
}

\author{
By Takeshi OTSUKA ${ }^{1,2}$ and Yoshiki CHUJO ${ }^{2, *}$
}

Hybridization of amphiphilic polymer and inorganic nanocrystal was examined aiming for improvement of thermal and optical properties of the organic polymer used. Optically transparent and homogeneous hybrids of poly(vinylpyrrolidone) (PVP) and zirconium oxide nanocrystals $\left(\mathrm{ZrO}_{2}-\mathrm{NCs}\right)$ were prepared through a water/methanol solution. Hydrogen bonding interactions between amide groups of PVP and $\mathrm{Zr}-\mathrm{OH}$ groups from $\mathrm{ZrO}_{2}-\mathrm{NC}$ were confirmed in the hybrids obtained. Thermal properties of the hybrids were improved with an increase of the $\mathrm{ZrO}_{2}-\mathrm{NC}$ content. In this research, $\mathrm{ZrO}{ }_{2}-\mathrm{NCs}$ in PVP matrix showed fine dispersion state. As expected, refractive index of the hybrids increased with $\mathrm{ZrO}_{2}-\mathrm{NC}_{\text {concentration }}$ and the refractive index variations follow the Lorentz-Lorenz relation.

KEY WORDS: Zirconium Oxide / Nanocrystal / Poly(vinylpyrrolidone) / Hybrid / Thermal Resistance / Refractive Index /

Organic-inorganic hybrids have recently received considerable attention in the field of material science and technology. ${ }^{1-5}$ Sometimes, the characteristics of nanocrystals are different from those of the bulk materials and result in unique properties. ${ }^{6-9}$ One of the most distinctive advantages of hybrids is their optical transparency. Because of the dispersion of nanometer-sized components, which is shorter wavelength than visible light and even near ultraviolet light, scattering loss would be avoided. ${ }^{10}$

Two approaches have been reported for the preparation of organic-inorganic hybrids. The first method is to incorporate organic polymer into inorganic matrices using a sol-gel method. The sol-gel treatment of metal alkoxides is quite a versatile approach to the preparation of hybrid materials. ${ }^{11}$ It is possible to prepare the inorganic oxide at ambient temperature by initial hydrolysis of the metal alkoxide and subsequent condensation by solvent evaporation, resulting in the formation of the three-dimensional inorganic oxide matrix. By introducing a covalent bond or a physical interaction between the organic polymer and inorganic material, transparent and homogeneous hybrids can be obtained. There are many reports about the synthesis of transparent hybrids utilizing hydrogen bonding interactions. ${ }^{12-14}$ However, it is difficult to incorporate organic polymers into inorganic matrices such as $\mathrm{TiO}_{2}, \mathrm{Al}_{2} \mathrm{O}_{3}$ and $\mathrm{ZrO}_{2}$ in a nanometer scale, because the rate of the sol-gel reaction of these alkoxides should be so fast. Also the inorganic domain in the hybrid obtained by the sol-gel method is amorphous form and optical property (especially refractive index) is relatively low. These are disadvantages for preparing optical functionalized hybrids.

The other method of preparing transparent hybrid was developed by incorporating inorganic nanocrystals into polymer matrices. ${ }^{15}$ A perfect dispersion of nanocrystals in solvents without agglomerates or aggregates is crucial for the fabrication of high performance organic-inorganic hybrids. Metal oxide nanocrystals are especially difficult to disperse homogeneously in organic polymers. To improve the miscibility of inorganic nanocrystals and organic polymers, the synthesis of metal oxide nanocrystals by non-aqueous sol-gel routes has been developed. ${ }^{16-20}$ Organic groups attached to the surface of the nanocrystals prevent the formation of aggregates and make their polarity adjustable to the medium.

$\mathrm{ZrO}_{2}$ nanocrystals have not only chemical inertness and excellent mechanical properties but also high refractive index and thermal stability. There are a few reports for the synthesis of the crystalline $\mathrm{ZrO}_{2}$ with average particle sizes below $5 \mathrm{~nm} .{ }^{21,22}$ In these cases, the $\mathrm{ZrO}_{2}$ dispersions are colored, which restricts their application potential. Zhou et al. ${ }^{20}$ reported a colorless dispersion of $\mathrm{ZrO}_{2}$ nanocrystals, which can be used for the fabrication of organic-inorganic hybrid materials for optical applications. However, this process leads to an organic surfactant attached on $\mathrm{ZrO}_{2}$ nanocrystals, and the thermal stability of the organic-inorganic hybrids utilized these $\mathrm{ZrO}_{2}$ nanocrystals decreases due to pyrolysis of the organic component. In general, large particles above $20 \mathrm{~nm}$ induce the optical scattering of inorganic particles and responsible for opacity so that optical applications of the hybrids are limited in thin films. On the other hand, small particles less than $10 \mathrm{~nm}$ can avoid Rayleigh scattering and be incorporated into a transparent polymer matrix. Only very few examples regarding the homogeneous water dispersions of highly crystalline and $\mathrm{ZrO}_{2}$ nanocrystals have been reported. Recently, by utilizing an artifice of manufacture process, we got nonaggregated tetragonal $\mathrm{ZrO}_{2}$ nanocrystals $(3 \mathrm{~nm})$ in water solution. ${ }^{23,24}$ This $\mathrm{ZrO}_{2}$ nanocrystal aqueous sol is colorless and suitable for preparation of water-soluble polymer and zirconium oxide hybrid materials.

In this paper, transparent and homogeneous hybrids of poly(vinylpyrrolidone) (PVP) and zirconium oxide nanocrystal $\left(\mathrm{ZrO}_{2}-\mathrm{NC}\right)$ were prepared utilizing the hydrogen bonding

\footnotetext{
Sumitomo Osaka Cement Co., LTD., 585, Toyotomi-cho, Funabashi 274-8601, Japan

${ }^{2}$ Department of Polymer Chemistry, Graduate School of Engineering, Kyoto University, Katsura, Nishikyo-ku, Kyoto 615-8510, Japan

*To whom correspondence should be addressed (Tel: +81-75-383-2604, Fax: +81-75-383-2607, E-mail: chujo@chujo.synchem.kyoto-u.ac.jp).
} 
interactions between the amide groups of PVP and the $\mathrm{Zr}-\mathrm{OH}$ groups from $\mathrm{ZrO}_{2}-\mathrm{NC}$. The chemical structures, morphology, thermal and optical properties of the prepared hybrids were examined. The effects of the PVP and $\mathrm{ZrO}_{2}-\mathrm{NC}$ content on the properties of the hybrids would be also discussed.

\section{EXPERIMENTAL}

\section{Materials}

Poly(vinylpyrrolidone) (PVP) with average molecular weight 40,000 was purchased from Tokyo Chemical Industry Co., Ltd. Poly(2-methyl-2-oxazoline) (PMeOZO) $\left(M_{\mathrm{n}}=6,300\right.$, $M_{\mathrm{w}} / M_{\mathrm{n}}=1.64$, polystyrene standard; eluent, DMF) was prepared by ring-opening polymerization of 2-methyl-2-oxazoline initiated by methyl p-toluenesulfonate. Poly(2-ethyl-2oxazoline) (PEtOZO) with average molecular weight 50,000 was purchased from Aldrich. Zirconium oxide nanocrystals $\left(\mathrm{ZrO}_{2}-\mathrm{NC}\right)$ sol, ${ }^{23}$ which contained $13.1 \mathrm{wt} \% \mathrm{ZrO}_{2}$ with chloride anion and $10.0 \mathrm{wt} \% \mathrm{ZrO}_{2}$ with acetic anion were obtained from Sumitomo Osaka Cement Co., Ltd. Methanol was dried and distilled from magnesium methoxide and stored under nitrogen. The other reagents were used as supplied.

\section{Measurements}

Powder X-ray diffraction patterns (XRD) were recorded on a Mini Flex/AW (Rigaku) using $\mathrm{Cu}-\mathrm{K}_{\alpha}$ radiation $(\lambda=$ $1.5406 \AA$ ). Fourier transform infrared (FT-IR) spectra were obtained using a Perkin Elmer 2000 infrared spectrometer by a $\mathrm{KBr}$ pellet method. Scanning electron microscopy (SEM) measurements were conducted using a JSM-5600B system (JEOL). The surface images were measured using a tapping mode atomic force microscopy (TM-AFM) (SPA 400, SEIKO Instruments Inc.) operating at room temperature. Height and phase images were recorded simultaneously. Nanoprobe cantilevers (SI-DF20, SEIKO Instruments Inc.) were utilized. Transmission electron microscopy (TEM) was performed with a JEM-2100F microscopy (JEOL) at $200 \mathrm{kV}$. Specimens were prepared cutting by use of focused ion beam (FIB) (SMI2050, SEIKO Instruments Inc.). The size of the $\mathrm{ZrO}_{2}-\mathrm{NCs}$ dispersed in water was determined by dynamic light scattering (DLS) using FPAR-1000 (Otsuka Electronics Co., Ltd.).

Differential scanning calorimetry (DSC) thermograms were obtained with a DSC200 (SEIKO Instruments Inc.) at a heating rate of $10^{\circ} \mathrm{C} / \mathrm{min}$ under nitrogen atmosphere. Thermogravimetric analysis (TGA) was performed using a TGA/DTA6200 (SEIKO Instruments Inc.) at a heating rate of $10^{\circ} \mathrm{C} / \mathrm{min}$ in air.

UV-visible transmission spectra were measured with a model MPS-2000 multipurpose spectrometer (Shimadzu). The refractive index was determined by an Abbe refract-meter using a DR-M4 (ATAGO Co., Ltd.).

\section{Preparation of PVP/ZrO 2 -NC Hybrids}

In a typical experiment, methanol was added into $\mathrm{ZrO}_{2}-\mathrm{NC}$ aqueous sol. To this solution, the PVP was dissolved. The resulting solution was stirred at room temperature for $1 \mathrm{~h}$. Then, the resulting solution was placed in a polypropylene

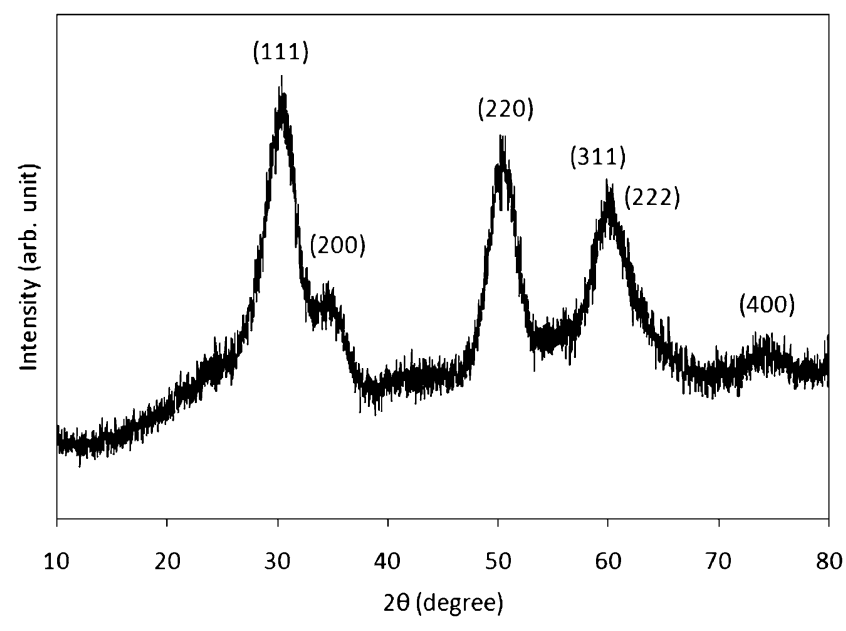

Figure 1. XRD pattern of the $\mathrm{ZrO}_{2}-\mathrm{NCs}$.

container and left in an oven at $60{ }^{\circ} \mathrm{C}$ to evaporate the solvent. Finally, the resulting hybrids were heated under reduced pressure at $80^{\circ} \mathrm{C}$ for $48 \mathrm{~h}$ to remove the remaining methanol and water completely. The other amphiphilic polymer (PMeOZO or PEtOZO) and $\mathrm{ZrO}_{2}-\mathrm{NC}$ hybrids were obtained by the same method.

\section{RESULTS AND DISCUSSION}

\section{Characterizations of $\mathrm{ZrO}_{2}$-NCs and Aqueous Sol}

A typical XRD pattern (Figure 1) indicates that the $\mathrm{ZrO}_{2}-$ NCs were highly crystalline and phase pure. The pattern of tetragonal phase $\mathrm{ZrO}_{2}$ was observed and average crystallite size was calculated as $3 \mathrm{~nm}$ from the peak of (220) reflection using Scherrer equation. According to literature, $\mathrm{ZrO}_{2}$ can adopt three different crystalline structures. Tetragonal phase, which is normally stable at high temperature for large grain ceramics has been observed stable or metastable at room temperature. However, these $\mathrm{ZrO}_{2}-\mathrm{NCs}$ have tetragonal phase which means the lower surface energy of tetragonal phase results in the stability of tetragonal structure at room temperature. ${ }^{25}$ Because the average diameter of $\mathrm{ZrO}_{2}-\mathrm{NCs}$ is about $3 \mathrm{~nm}$ based on the TEM micrograph (Figure 2), it can be concluded that the $\mathrm{ZrO}_{2}$-NCs are single crystalline.

Figure 3 represents the photograph of the $\mathrm{ZrO}_{2}-\mathrm{NCs}$ aqueous sol, which has highly transparency without the particle aggregation. Table I gives a survey of the characteristics for $\mathrm{ZrO}_{2}-\mathrm{NCs}$ and aqueous sol.

\section{Preparation of $\mathrm{PVP} / \mathrm{ZrO}_{2}$-NC Hybrids}

$\mathrm{ZrO}_{2}-\mathrm{NCs}$ were incorporated into a PVP matrix on the nanometer scale without covalent bonds being formed between PVP and the $\mathrm{ZrO}_{2}-\mathrm{NCs}$. This is because the amide group of PVP forms hydrogen bonds with the $\mathrm{Zr}-\mathrm{OH}$ groups of $\mathrm{ZrO}_{2}$ NCs. The results are shown in Table II. Transparent and homogeneous hybrids were obtained in all samples. The calculated polymer content was almost the same as that measured from TGA analysis in air. 


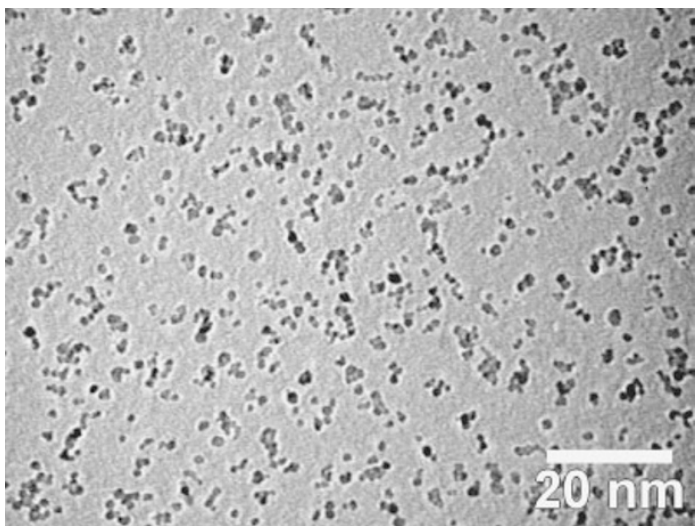

Figure 2. TEM micrograph of the $\mathrm{ZrO}_{2}-\mathrm{NCs}$

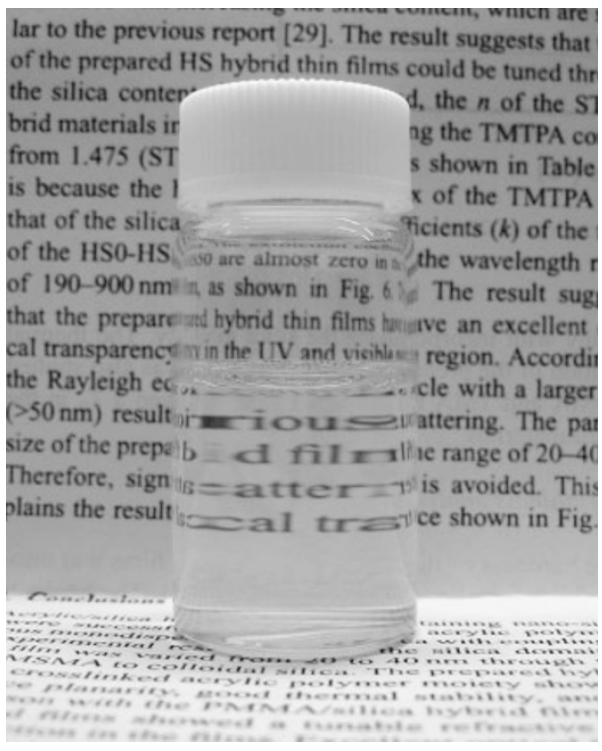

Figure 3. Photograph of aqueous sol containing $13.1 \mathrm{wt} \% \mathrm{ZrO}_{2}-\mathrm{NCs}$.

\section{Preparation of PMeOZO or PEtOZO/ZrO $\mathrm{ZO}_{2}-\mathrm{NC}$ Hybrids}

$\mathrm{ZrO}_{2}-\mathrm{NCs}$ can also be incorporated into amide group polymers such as $\mathrm{PMeOZO}$ or PEtOZO by adding $\mathrm{ZrO}_{2}-\mathrm{NCs}$ with chloride anion or acetate anion. The results are shown in Table III. The $\mathrm{ZrO}_{2}$-NCs with chloride anion could be perfectly miscible with the PMeOZO (Run 7, 8). The $\mathrm{Zr}-\mathrm{OH}$ groups of the $\mathrm{ZrO}_{2}-\mathrm{NCs}$ and amide groups of the PMeOZO demonstrated hydrogen bonding interactions, which assisted uniform dispersion of each segment. On the other hand, PEtOZO and high content $\mathrm{ZrO}_{2}$-NCs with chloride anion hybrid (Run 10) showed phase separation, which was due to the change of miscibility between the PEtOZO and the $\mathrm{ZrO}_{2}$ NCs. Because the PEtOZO has more hydrophobic property compared with the PMeOZO, the surface property of the $\mathrm{ZrO}_{2}$ NCs changed from hydrophilic to hydrophobic by acetate anion, which led to the $\mathrm{ZrO}_{2}$-NCs dispersion into the PEtOZO (Run 11, 12). It was confirmed that the transparent and homogeneous hybrids were obtained by utilizing hydrogen bonding interactions and controlling hydrophilic and hydrophobic properties of the $\mathrm{ZrO}_{2}-\mathrm{NCs}$ 'surface.
Table I. Characteristics of the $\mathrm{ZrO}_{2}-\mathrm{NCs}$ and aqueous sol

\begin{tabular}{clc}
\hline & Particle size $(\mathrm{nm})$ & ca. 3 \\
\multirow{2}{*}{$\mathrm{ZrO}_{2}-\mathrm{NCs}$} & Crystalline phase & 170 \\
& $\mathrm{BET} \mathrm{S} \mathrm{N}^{2}\left(\mathrm{~m}^{2} / \mathrm{g}\right)$ & 11.0 \\
& $\mathrm{OH}$ Surface Density $\left(\mathrm{OH} / \mathrm{nm}^{2}\right)^{\mathrm{a}}$ & 13.1 \\
$\mathrm{ZrO}_{2}-\mathrm{NC}$ & $\mathrm{ZrO}_{2}-\mathrm{NC}$ Concentration $(\mathrm{wt} \%)$ & $\mathrm{Cl}^{-}$ \\
aqueous sol & Counter lon & 2.0 \\
& $\mathrm{pH}$ & $4.8 \pm 1.2$ \\
\hline
\end{tabular}

${ }^{a}$ Determined by TGA. ${ }^{26}$ betermined by DLS measurement.

Table II. Preparation of $\mathrm{PVP} / \mathrm{ZrO}_{2}-\mathrm{NC}$ hybrids

\begin{tabular}{|c|c|c|c|c|c|c|}
\hline \multirow{2}{*}{ Run } & \multirow{2}{*}{$\begin{array}{l}\text { PVP } \\
(\mathrm{g})\end{array}$} & \multirow{2}{*}{$\begin{array}{c}\mathrm{ZrO}_{2}-\mathrm{NCs} \\
\text { aqueous sol } \\
\text { (g) }\end{array}$} & \multirow{2}{*}{$\begin{array}{c}\text { Methanol } \\
(\mathrm{ml})\end{array}$} & \multirow{2}{*}{ Appearance } & \multicolumn{2}{|c|}{ Ceramic yield (wt \%) } \\
\hline & & & & & Calcd. & Obsd. ${ }^{\mathrm{b}}$ \\
\hline 1 & 1.00 & 0.00 & 10.0 & transparent & 0 & 0 \\
\hline 2 & 0.85 & 1.15 & 9.0 & transparent & 15.0 & 15.8 \\
\hline 3 & 0.70 & 2.29 & 9.5 & transparent & 30.0 & 29.8 \\
\hline 4 & 0.50 & 3.82 & 10.0 & transparent & 50.0 & 48.5 \\
\hline 5 & 0.30 & 5.34 & 12.5 & transparent & 70.0 & 67.0 \\
\hline 6 & 0.20 & 6.11 & 12.5 & almost transparent & 80.0 & 76.2 \\
\hline
\end{tabular}

a $13.1 \mathrm{wt} \% \mathrm{ZrO}_{2}-\mathrm{NC}$ aqueous sol including chloride anion was used. Sol $\mathrm{pH}$ was 2.0. ${ }^{\text {b }}$ Determined by TGA.

Table III. Preparation of amphiphilic polymer $/ \mathrm{ZrO}_{2}-\mathrm{NC}$ hybrids

\begin{tabular}{|c|c|c|c|c|c|c|}
\hline Run & $\begin{array}{l}\text { Polym } \\
\text { (g) }\end{array}$ & & $\begin{array}{c}\mathrm{ZrO}_{2} \mathrm{NC} \\
\text { aqueous sola } \\
\text { (g) }\end{array}$ & $\begin{array}{c}\text { Counter lon } \\
\text { of } \mathrm{ZrO}_{2} \text { surface }\end{array}$ & $\begin{array}{l}\text { Methanol } \\
\quad(\mathrm{ml})\end{array}$ & Appearance \\
\hline 7 & $\mathrm{PMeOZO}$ & 0.85 & 1.50 & \multirow{4}{*}{$\mathrm{Cl}^{-b}$} & 9.0 & Transparent \\
\hline 8 & PMeOZO & 0.30 & 7.00 & & 12.5 & Transparent \\
\hline 9 & PEtOZO & 0.85 & 1.50 & & 9.0 & Transparent \\
\hline 10 & PEtOZO & 0.30 & 7.00 & & 12.5 & Phase separate \\
\hline 11 & PEtOZO & 0.85 & 1.50 & \multirow{2}{*}{$\mathrm{CH}_{3} \mathrm{COO}^{-\mathrm{c}}$} & 9.0 & Transparent \\
\hline 12 & PEtOZO & 0.30 & 7.00 & & 12.5 & Transparent \\
\hline
\end{tabular}

${ }^{\mathrm{a}} 10.0 \mathrm{wt} \% \mathrm{ZrO}_{2}-\mathrm{NC}$ aqueous sol was used. ${ }^{\mathrm{b}} \mathrm{Sol} \mathrm{pH}$ was 2.0. ${ }^{\mathrm{c}} \mathrm{Sol} \mathrm{pH}$ was 2.5 .

\section{Chemical Structures of PVP/ZrO $\mathrm{ZO}_{2}-\mathrm{NC}$ Hybrids}

XRD patterns of the hybrids with different contents of $\mathrm{ZrO}_{2}$ NCs are represented in Figure 4. Sharp peaks can be assigned to a tetragonal $\mathrm{ZrO}_{2}$ structure and amorphous form like pattern could be attributable to PVP.

The strength of the hydrogen bonding interactions in PVP/ $\mathrm{ZrO}_{2}-\mathrm{NC}$ hybrids was confirmed by FT-IR. It is believed that the amide carbonyl stretching peak of PVP was shifted to lower wavenumbers region when hydrogen bonding interactions were induced between amide groups of PVP and the surface $\mathrm{Zr}-\mathrm{OH}$ of the $\mathrm{ZrO}_{2}-\mathrm{NCs}$. As shown in Figure 5, the amide carbonyl stretching band of PVP was gradually shifted from $1680 \mathrm{~cm}^{-1}$ to $1645 \mathrm{~cm}^{-1}$ upon hybridization with $\mathrm{ZrO}_{2}-\mathrm{NCs}$, which should be evidence of the hydrogen bonding interactions. This result indicates that the $\mathrm{ZrO}_{2}$-NCs were dispersed in the PVP homogeneously through the hydrogen bonding interactions.

\section{Morphology of PVP/ZrO}

The homogeneity of the organic and inorganic phases was examined by SEM and TM-AFM measurements. As shown in 


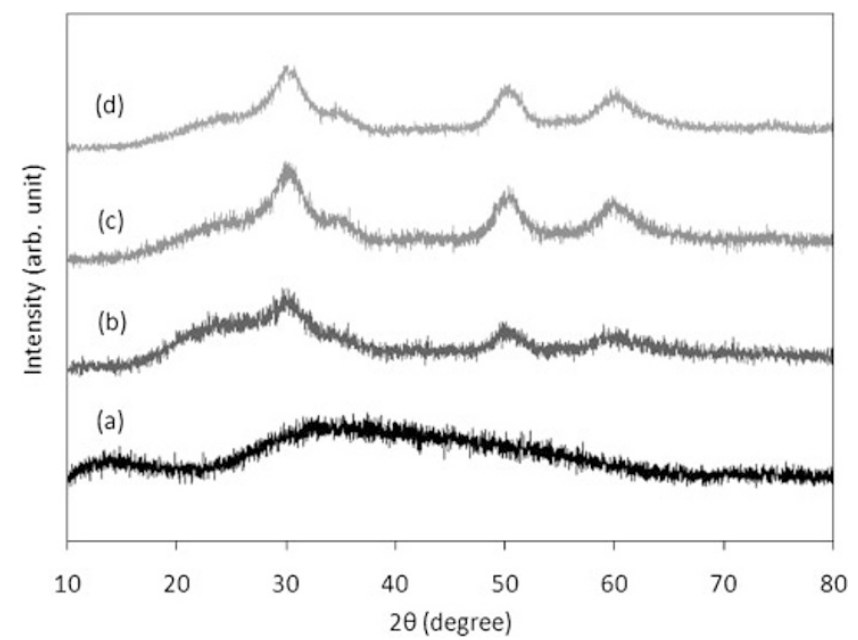

Figure 4. XRD patterns of (a) the pristine PVP (Run 1), (b) Run 2 (PVP/ $15 \mathrm{wt} \% \mathrm{ZrO}_{2}$ ), (c) Run 4 (PVP/50 wt \% $\mathrm{ZrO}_{2}$ ) and (d) Run 6 (PVP/ $80 \mathrm{wt} \% \mathrm{ZrO}_{2}$ ).
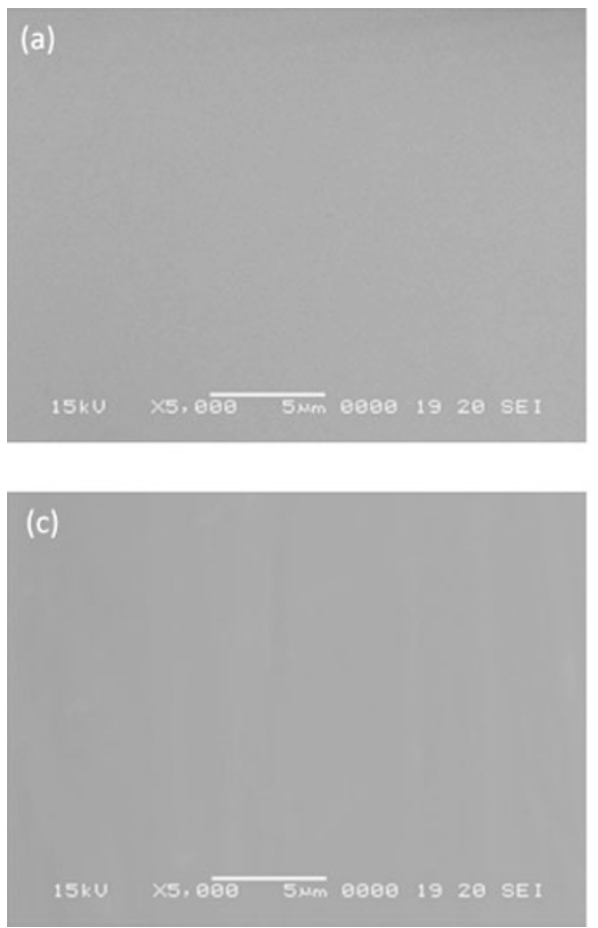

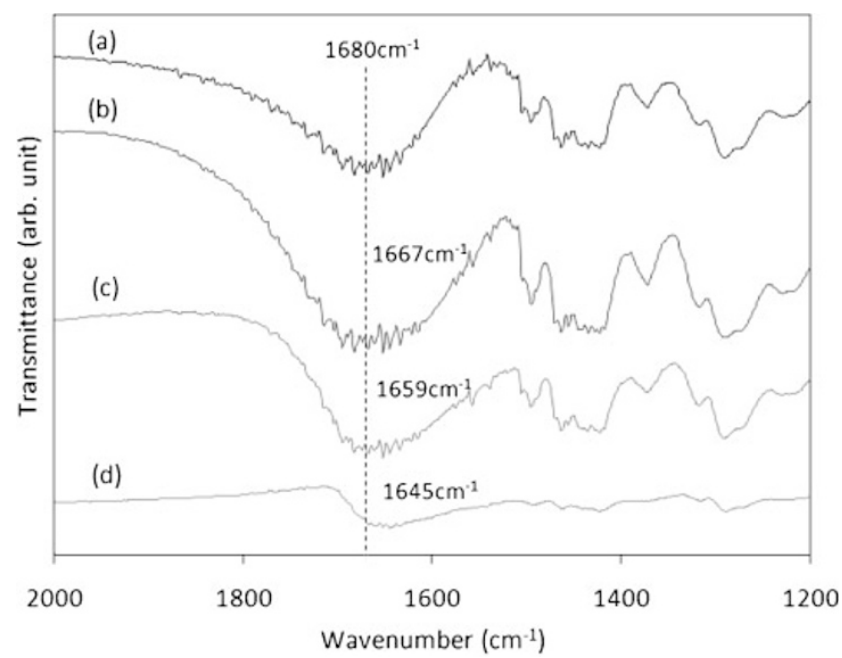

Figure 5. FT-IR spectra of (a) the pristine PVP (Run 1), (b) Run 3 (PVP/ 30 wt $\% \mathrm{ZrO}_{2}$ ), (c) Run $4\left(\mathrm{PVP} / 50 \mathrm{wt} \% \mathrm{ZrO}_{2}\right.$ ) and (d) Run 6 (PVP/ $80 \mathrm{wt} \% \mathrm{ZrO}_{2}$ ).
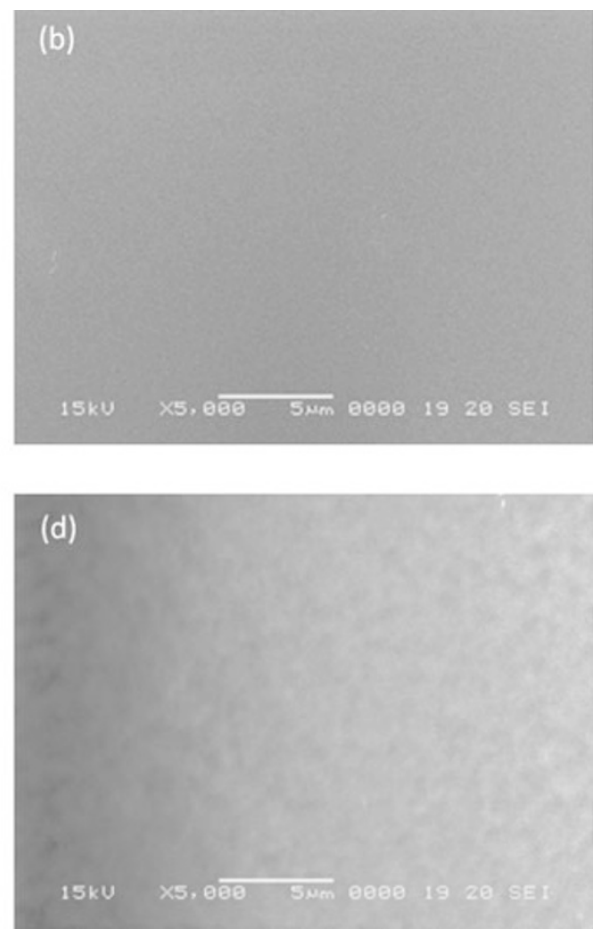

Figure 6. SEM images of (a) Run $3\left(\mathrm{PVP} / 30 \mathrm{wt} \% \mathrm{ZrO}_{2}\right)$, (b) Run $4\left(\mathrm{PVP} / 50 \mathrm{wt} \% \mathrm{ZrO}_{2}\right)$, (c) Run $5\left(\mathrm{PVP} / 70 \mathrm{wt} \% \mathrm{ZrO}{ }_{2}\right)$ and (d) Run $6(\mathrm{PVP} / 80 \mathrm{wt} \% \mathrm{ZrO})_{2}$.

Figure 6 , the $\mathrm{ZrO}_{2}-\mathrm{NC}$ aggregation or phase separation were not observed in all samples, however, in run 6 (Figure 6d), the crenellated surface topology was confirmed. Figure 7 shows TM-AFM images of the obtained PVP $/ \mathrm{ZrO}_{2}-\mathrm{NC}$ hybrids. The height image of the hybrid with $80 \mathrm{wt} \% \mathrm{ZrO}_{2}$ (Run 6) had a high surface roughness (Figure 7d: TM-AFM image). This means that the PVP molecular chains were not able to cover the $\mathrm{ZrO}_{2}-\mathrm{NC}$ surface perfectly because of high content of $\mathrm{ZrO}_{2}$ NCs. In contrast, as shown in Figure $7 \mathrm{a}-\mathrm{c}$, the hybrids containing below $70 \mathrm{wt} \% \mathrm{ZrO}_{2}-\mathrm{NCs}$ showed high homogeneous dispersion of $\mathrm{ZrO}_{2}-\mathrm{NCs}$ in the PVP matrix and extremely smooth surface at nano-meter level.

For the hybrid with $30 \mathrm{wt} \%$ of $\mathrm{ZrO}_{2}-\mathrm{NCs}$ (Run 3), the TEM measurement was conducted. As shown in Figure 8, the distribution of the inorganic phase and the organic phase was clearly observed as dark spots and bright spots, respectively. This result strongly indicates the homogeneous miscibility of $\mathrm{PVP} / \mathrm{ZrO}_{2}-\mathrm{NC}$ hybrids.

\section{Thermal Properties of PVP/ZrO $/ \mathrm{CO}_{2}-\mathrm{NC}$ Hybrids}

The thermal stability of the hybrids of PVP and $\mathrm{ZrO}_{2}-\mathrm{NCs}$ was examined by TGA. Some examples of the results are 

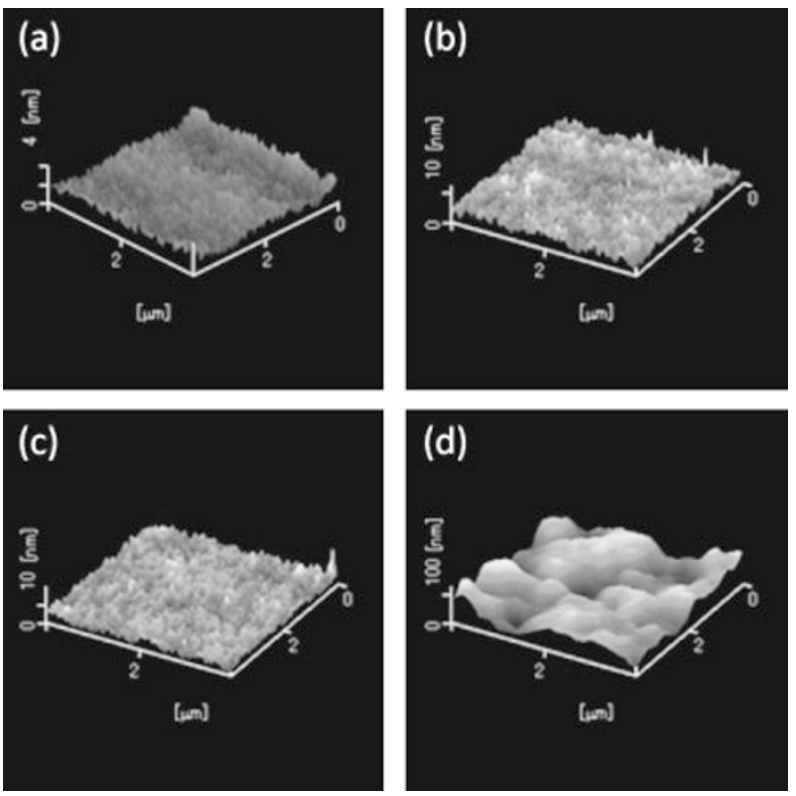

Figure 7. TM-AFM images of (a) the pristine PVP (Run 1), (b) Run 4 (PVP/ 50 wt \% $\mathrm{ZrO}_{2}$ ), (c) Run 5 (PVP/70 wt \%ZrO 2 ) and (d) Run 6 (PVP/ $80 \mathrm{wt} \% \mathrm{ZrO}_{2}$ )

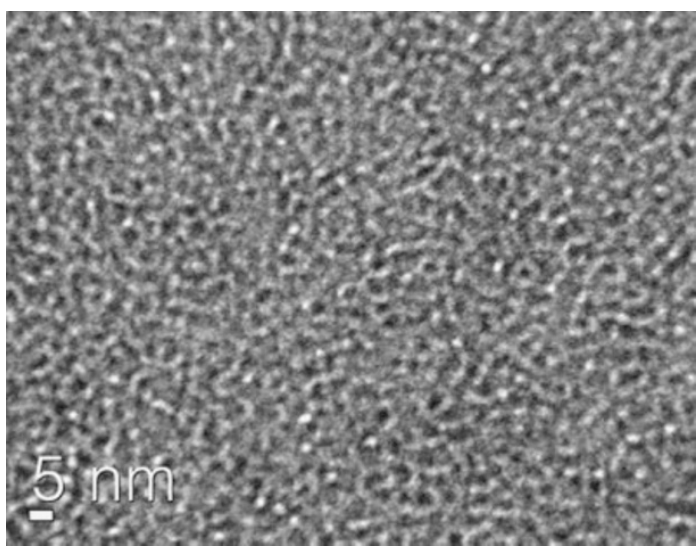

Figure 8. TEM image of Run $3\left(\mathrm{PVP} / 30 \mathrm{wt} \% \mathrm{ZrO}_{2}\right)$.

shown in Figure 9. The thermal stability of PVP was improved by hybridization with $\mathrm{ZrO}_{2}$ due to the incorporation of $\mathrm{ZrO}_{2}$ NCs into the PVP matrix homogeneously.

Glass transition behaviors of $\mathrm{PVP}$ and $\mathrm{PVP} / \mathrm{ZrO}_{2}-\mathrm{NC}$ hybrids were checked by DSC (Figure 10). The glass transition temperature $\left(T_{\mathrm{g}}\right)$ of PVP is $163^{\circ} \mathrm{C}$ (Figure 10a). On the other hand, it is shown that $T_{\mathrm{g}}$ increased with $\mathrm{ZrO}_{2}-\mathrm{NC}$ loading and was edgingly indecisive. These results indicate that $\mathrm{ZrO}_{2}-\mathrm{NCs}$ were dispersed at nano-meter scale in the PVP matrix so that the segmental motion of PVP was inhibited by the $\mathrm{ZrO}_{2}-\mathrm{NCs}$.

\section{Optical Properties of PVP/ZrO $\mathrm{Zr}_{2}-\mathrm{NC}$ Hybrids}

Optical transparency of $\mathrm{PVP} / \mathrm{ZrO}_{2}-\mathrm{NC}$ hybrid films was characterized by UV-vis spectra. Figure 11 shows the optical transmittance of a quartz glass substrate coated with about $400 \mathrm{~nm}$ thick of $\mathrm{PVP} / \mathrm{ZrO}_{2}-\mathrm{NC}$ hybrid films (Run 1-6). The

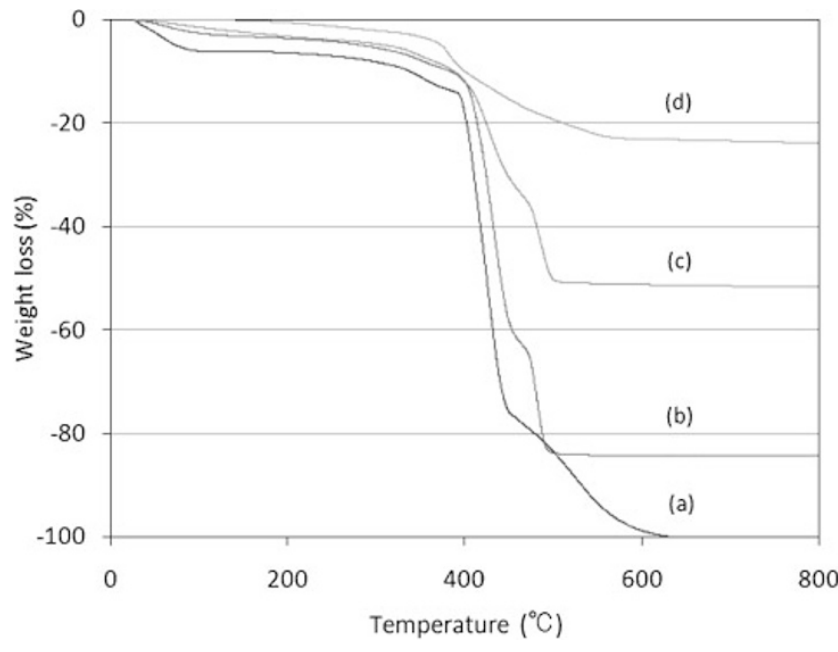

Figure 9. TGA traces of (a) the pristine PVP (Run 1), (b) Run 2 (PVP/ 15 wt $\% \mathrm{ZrO}_{2}$ ), (c) Run 4 (PVP $/ 50$ wt $\% \mathrm{ZrO}_{2}$ ) and (d) Run 6 (PVP/ $80 \mathrm{wt} \% \mathrm{ZrO}_{2}$ ).

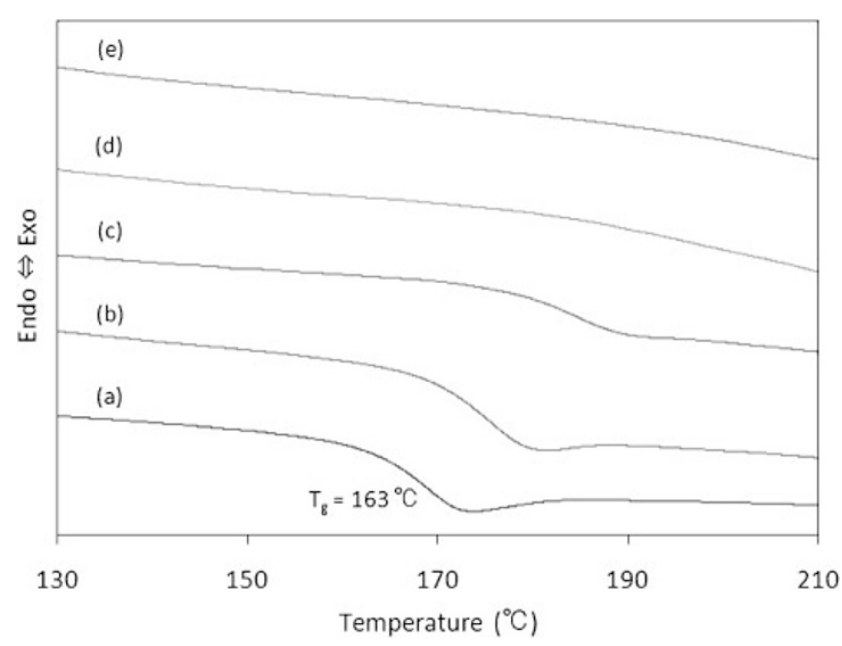

Figure 10. DSC thermograms of (a) the pristine PVP (Run 1), (b) Run 2 (PVP/15wt \% $\mathrm{ZrO}_{2}$ ), (c) Run 3 (PVP/30wt \%ZrO $)$, (d) Run 4 (PVP/50 wt \%ZrO ${ }_{2}$ ) and (e) Run 5 (PVP/70wt \% $\mathrm{ZrO}_{2}$ ).

films were formed on only one side of the substrate by spin coating. It is observed that optical transmittance of the hybrid film was above $90 \%$ in the visible light region, although it falls slightly by absorption of $\mathrm{ZrO}_{2}$. This result also confirms that the $\mathrm{ZrO}_{2}-\mathrm{NCs}$ were uniformly distributed in the hybrids.

The film composition determines the refractive index of the hybrid film. There are many models describing the relationship between the refractive index of a composite film and its components. The Lorentz-Lorenz relation has been a frequently adopted model. ${ }^{27-29}$ It is as follows:

$$
\frac{n_{\text {film }}^{2}-1}{n_{\text {film }}^{2}+2}=f_{A} \frac{n_{A}^{2}-1}{n_{A}^{2}+2}+f_{B} \frac{n_{B}^{2}-1}{n_{B}^{2}+2}
$$

where $n_{\text {film }}$ is refractive index of the composite film, $n_{A}$ and $n_{B}$ are the refractive indices of each component, and $f_{A}$ and $f_{B}$ are the volume fraction of each component. Applying this equation 


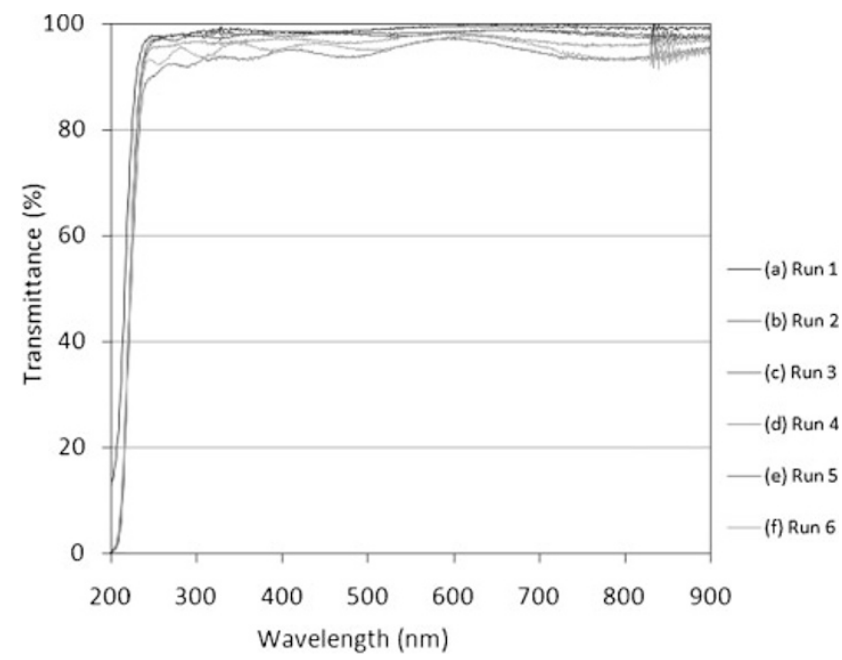

Figure 11. Optical transmittance of (a) the pristine PVP (Run 1), (b) Run 2 (PVP/15 wt \% $\mathrm{ZrO}_{2}$ ), (c) Run $3(\mathrm{PVP} / 30 \mathrm{wt} \% \mathrm{ZrO}$ ), (d) Run 4 (PVP/50 wt \% $\mathrm{ZrO}_{2}$ ), (e) Run 5 (PVP/70 wt $\% \mathrm{ZrO}_{2}$ ) and (f) Run 6 (PVP/80 wt \% $\mathrm{ZrO}_{2}$ ).

to calculate the composition of the film, we have to assume that the film is a compositionally homogeneous single layer. The compositions calculated by using eq 1 (assuming $n_{\mathrm{PVP}}=1.53, \rho_{\mathrm{PVP}}=1.22 \mathrm{~g} / \mathrm{cm}^{3}, n_{\mathrm{ZrO}_{2}}=2.20$ and $\rho_{\mathrm{ZrO}_{2}}=$ $5.96 \mathrm{~g} / \mathrm{cm}^{3}$ ) were compared with the actual compositions of films as determined by Abbe refract-meter shown in Figure 12. The refractive index at $589 \mathrm{~nm}$ of the $\mathrm{PVP} / \mathrm{ZrO}_{2}-\mathrm{NC}$ hybrid films increased from 1.52 to 1.72 with the weight content of $\mathrm{ZrO}_{2}-\mathrm{NCs}$ from 0 to $80 \mathrm{wt} \%$. It could be confirmed that the calculated refractive index on the Lorentz-Lorenz relation was in good agreement with the experimental value of $\mathrm{PVP} / \mathrm{ZrO}_{2}$ NC hybrid film. Belleville et al. ${ }^{30}$ and Shen et al. ${ }^{31,32}$ reported that maximum refractive index of $\mathrm{PVP} / \mathrm{ZrO}_{2}$ composites was 1.72. However, they used $\mathrm{ZrO}_{2}$ with the particle sizes above $15 \mathrm{~nm}$ so that Rayleigh scattering from the $\mathrm{ZrO}_{2}$ nano-particles could not avoid and the optical application of such nanocomposite was limited in thin film. In this paper, we utilized the single nano-sized $\mathrm{ZrO}_{2}$ crystals so that hybrid materials with not only high refractive index (1.72) but also highly transparency could be obtained by hybridization of PVP and $\mathrm{ZrO}_{2}-\mathrm{NCs}$.

\section{CONCLUSION}

Transparent and homogeneous hybrids were prepared utilizing hydrogen bonding interactions between the amide groups of PVP and $\mathrm{Zr}-\mathrm{OH}$ groups of $\mathrm{ZrO}_{2}-\mathrm{NCs}$. The $\mathrm{ZrO}_{2}-\mathrm{NCs}$ were dispersed well in the PVP matrix and demonstrated no aggregation and phase separation. Thermal stability and $T_{\mathrm{g}}$ of the hybrids increased with the $\mathrm{ZrO}_{2}$ content. The improvement of thermal properties implies that the $\mathrm{ZrO}_{2}-\mathrm{NCs}$ lead to a decrease in the segmental mobility of the PVP chain. The experimental refractive indices of the hybrids were good agreement with the Lorentz-Lorenz relation. The improvement of the refractive index of PVP was attained by incorporation

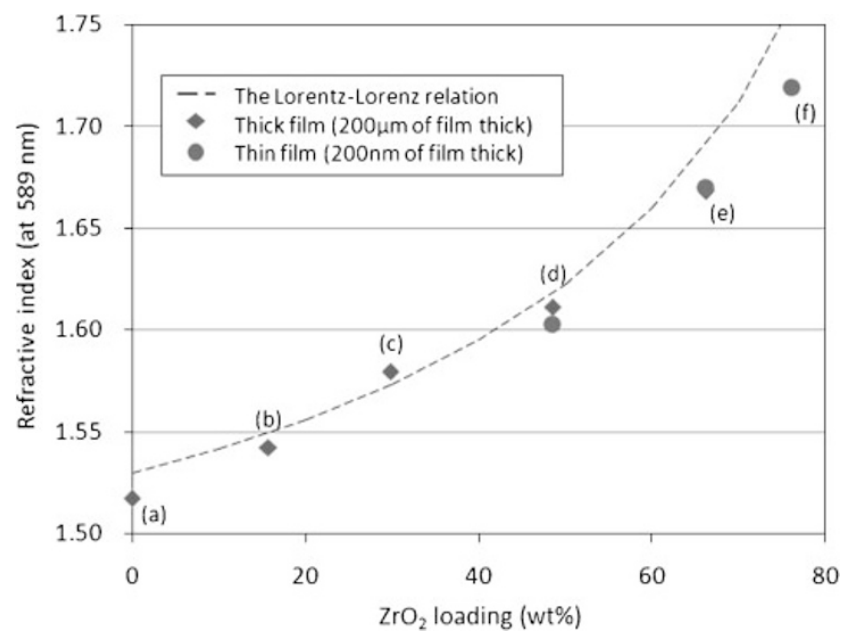

Figure 12. Refractive indices of (a) the pristine PVP (Run 1), (b) Run 2 (PVP/15 wt \%ZrO $\mathrm{Zr}_{2}$ ), (c) Run 3 (PVP/30wt \%ZrO $)_{2}$, (d) Run 4 (PVP $/ 50$ wt \%ZrO $\mathrm{Z}_{2}$ ), (e) Run $5\left(\mathrm{PVP} / 70 \mathrm{wt} \% \mathrm{ZrO}_{2}\right)$ and (f) Run 6 (PVP/80 wt \% $\mathrm{ZrO}_{2}$ ).

of the $\mathrm{ZrO}_{2}$-NCs. Multifunctional hybrid materials with high transparency, high refractive index and thermal stability were obtained by hybridization of amphiphilic polymer and inorganic nanocrystals.

Received: July 18, 2008

Accepted: September 2, 2008

Published: October 16, 2008

\section{REFERENCES}

1. B. M. Novak, Adv. Mater., 5, 422 (1993).

2. M. W. Ellsworth and B. M. Novak, J. Am. Chem. Soc., 113, 2756 (1991).

3. U. Schubert, N. Husing, and A. Lorenz, Chem. Mater., 7, 2010 (1995).

4. J. Wen and G. L. Wilkes, Chem. Mater., 8, 1667 (1996).

5. Y. Wei, D. Jin, D. J. Brennan, D. N. Rivera, Q. Zhuang, N. J. DiNardo, and K. Qiu, Chem. Mater., 10, 769 (1998).

6. G. Schmid, V. Maihack, F. Lantermann, and S. Peschel, J. Chem. Soc., Dalton Trans., 589 (1996).

7. L. Beecroft and C. K. Ober, Chem. Mater., 9, 1302 (1997).

8. R. C. Mucic, J. J. Storhoff, C. A. Mirkin, and R. L. Letsinger, J. Am. Chem. Soc., 120, 12674 (1998).

9. J. J. Storhoff, A. A. Lazarides, R. C. Mucic, C. A. Mirkin, R. L. Letsinger, and G. C. Schatz, J. Am. Chem. Soc., 122, 4640 (2000).

10. C. F. Bohren and D. R. Huffman, "Absorption and Scattering of Light by Small Particles," Wiley, New York, 1983.

11. C. J. Brinder and G. W. Scherer, Sol-Gel Science, "The Physics and Chemistry of Sol-Gel Processing," Academic Press, San Diego, 1990.

12. Y. Chujo and T. Saegusa, Adv. Polym. Sci., 100, 11 (1992).

13. Y. Chujo, H. Matsuki, S. Kure, T. Saegusa, and T. Yazawa, J. Chem. Soc., Chem. Commun., 635 (1994).

14. Y. Chujo, Curr. Opin. Solid State Mater. Sci., 1, 806 (1996).

15. M. Z. Rong, M. Q. Zhang, Y. X. Zheng, H. M. Zeng, R. Walter, and K. Friedrich, Polymer, 42, 167 (2001).

16. M. Niederberger and G. Granweitner, Chem.-Eur. J., 12, 7282 (2006).

17. M. Niederberger, G. Granweitner, F. Krumeich, R. Nesper, H. Colfen, and M. Antoniettei, Chem. Mater., 16, 1202 (2004).

18. N. Pinna, S. Grancharov, P. Beato, P. Bonville, M. Antonietti, and M. Niederberger, Chem. Mater., 17, 3044 (2005). 
19. J. H. Ba, J. Polleux, M. Antonietti, and M. Niederberger, Adv. Mater., 17, 2509 (2005).

20. S. Zhou, G. Garnweitner, M. Niederberger, and M. Antonietti, Langmuir, 23, 9178 (2007).

21. W. He, Z. G. Guo, and Y. K. Pu, Appl. Phys. Lett., 85, 896 (2004).

22. J. Joo, T. Yu, Y. W. Kim, H. M. Park, F. X. Wu, J. Z. Zhang, and T. Hyeon, J. Am. Chem. Soc., 125, 6553 (2003).

23. T. Kinoshita, JP Patent 2006-016236 (2006).

24. T. Kinoshita and T. Kawase, JP Patent 2007-099931 (2007).

25. Y. L. Zhang, X. J. Jin, Y. H. Rong, T. Y. Hsu (Xu Zuyao), D. Y. Jiang, and J. L. Shi, Mater. Sci. Eng., A, 438-440, 399 (2006).

26. Z. W. Wang, T. J. Wang, Z. W. Wang, and Y. Jin, J. Colloid Interface Sci., 304, 152 (2006).
27. X. Wang, H. Masumoto, Y. Someno, and T. Hirai, Thin Solid Films, 338, 105 (1996).

28. B. D. Fabes, D. P. Birnie, and B. J. J. Zelinski, III., Thin Solid Films, 254, 175 (1995).

29. A. Moujoud, Z. Saddiki, T. Touam, and S. I. Najafi, Thin Solid Films, 422, 161 (2002).

30. P. Belleville, C. Bonnin, and J. J. Priotton, J. Sol-Gel Sci. Technol., 19, 223 (2000).

31. J. Shen, Q. Zhang, J. Wang, T. Yang, Z. Deng, B. Zhou, and L. Chen, J. Sol-Gel Sci. Technol., 19, 271 (2000).

32. Q. Zhang, J. Shen, J. Wang, G. Wu, and L. Chen, Int. J. Inorg. Mater., 2, 319 (2000). 